\title{
Взаимодействие средств массовой информации и общества: анализ информационных повесток дня
}

\author{
Каминченко Д.И. \\ Национальный исследовательский Нижегородский \\ государственный университет им. Н.И. Лобачевского, \\ Россия, 603950, г. Нижний Новгород, пр. Гагарина, 23 \\ E-mail: ert1fg2@rambler.ru
}

\begin{abstract}
Аннотация. Цифровизация современного общества оказывает существенное воздействие на его публичное пространство, структурированное основными содержательно-смысловыми компонентами информационных повесток дня, важную роль в функционировании которого играют СМИ и современные социальные медиа. Несмотря на то, что данной теме уделено немало внимания как российских, так и зарубежных ученых, соотношение содержания повесток дня СМИ и социальных медиа изучено недостаточно. В связи с этим автором проведен сравнительный анализ информационных повесток разных СМИ и социальных медиа. Результаты исследования согласуются с существующим тезисом о дифференциации современного публичного пространства. Складывающиеся в нем коммуникативные и содержательно-смысловые поля характеризуются отличными друг от друга нарративами, при этом отмечено тематическое совпадение между содержанием новостной повестки дня телевизионного канала и повесткой дня современных социальных медиа. Установленные в ходе анализа показатели коэффициента сопряженности между информационными повестками дня СМИ и социальных медиа говорят об особенностях процесса установления медийной повестки дня и участия в нем различных политических и общественных акторов.
\end{abstract}

Ключевые слова: информационная повестка дня, информация, социальные медиа, общество, СМИ.

Для цитирования: Каминченко Д.И. 2020. Взаимодействие средств массовой информации и общества: анализ информационных повесток дня. Вопросы журналистики, педагогики, языкознания, 39 (4): 533-544. DOI 10.18413/2712-7451-2020-39-4-533-544

\section{Interaction of mass media and society: agenda analysis}

\author{
Dmitry I. Kaminchenko \\ Lobachevsky State University of Nizhni Novgorod \\ 23 Gagarin Avenue, Nizhnij Novgorod, 603950, Russia \\ E-mail: ert1fg2@rambler.ru
}

\begin{abstract}
The digitalization of modern society has a significant impact on its public space. Modern public space is structured by the main content-semantic components of agendas. The media and modern social media play an important role in the functioning of this communication space. Despite the fact that this topic has received a lot of attention from both Russian and foreign scientists, the relationship between the content of the agendas of the media and social media has been insufficiently studied. In this regard, the author has carried out a comparative analysis of the information agendas of various media and social media. The research results are consistent with the existing thesis on the differentiation of modern public space. The communicative and content-semantic fields that are formed in it are characterized by different narratives. A thematic coincidence between the content of the news agenda of a television channel and the agenda of modern social media is noted in the study. The indicators of the coefficient of contingency between the information agendas of the media and social media are established in the course of the
\end{abstract}


analysis. It indicates the peculiarities of the process of setting the media agenda and the participation of various political and social actors in this process.

Keywords: agenda, information, social media, society, media

For citation: Kaminchenko D.I. 2020. Interaction of mass Media and Society: agenda Analysis. Issues in Journalism, Education, Linguistics, 39 (4): 533-544 (in Russian). DOI 10.18413/2712-7451-2020-39-4533-544

\section{Введение}

Информация в современном обществе играет важнейшую роль в различных общественных процессах и отношениях. Контроль над информацией является значимой целью различных субъектов как общественного, так и политического пространства. Возможность оказывать воздействие на складывающиеся и разделяемые общественным большинством нарративы становится главным преимуществом в политической конкуренции. При этом информационное общество является еще и сетевым, что определяет специфику его публичного пространства: оно становится более динамичным и ситуативным. Более того, это публичное пространство в условиях избытка информации становится разделенным одновременно на несколько коммуникативных полей с разными, преобладающими в них нарративами.

В разных коммуникативных полях публичного пространства формируются и отличные друг от друга информационные повестки, т.е. перечни тем и вопросов (и их содержание), рассматриваемые участниками той или иной части публичного пространства в качестве наиболее значимых. Разность информационных повесток особенно наглядно проявляется в медийном пространстве, так как именно медийная повестка дня является выразителем интересов и настроений различных общественных и политических групп, а также профессиональных журналистов. Скорость обмена информацией и данными в современном обществе сделали эти отличия еще более существенными и динамичными, подверженными ситуативности и сетевизации в целом. Поэтому анализ содержания информационных повесток дня разных медиа является крайне актуальной задачей современной гуманитарной науки.

Вовлечение общества в процессы стремительной информатизации открыло и новые возможности для изучения общественных настроений, и повестки дня общества, т.е. выявления тех тем и вопросов, которые привлекают к себе особое внимание со стороны общества. Одним из важнейших «измерителей» подобных настроений, на наш взгляд, стали современные социальные медиа, информационная повестка дня которых может быть рассмотрена сегодня в качестве важнейшего (но не единственного) компонента общественной повестки. Содержание повестки дня социальных медиа может существенно расходиться с новостным и событийным контентом разных средств массовой информации. Различные СМИ по-разному отражают наиболее острые общественные темы, что актуализирует вопрос о степени соответствия наполнения повесток дня СМИ содержанию повестки дня социальных медиа. При этом необходимо учесть, что в условиях больших массивов данных о происходящих событиях, СМИ приходится отбирать те темы, которые наиболее актуальны и соответствуют принципам новостной политики. А сам процесс отбора новостных данных и распространения информации может зависеть в том числе и от типа политического режима, подразумевающего ту или иную степень вмешательства в этот процесс со стороны различных политических субъектов. Все это оказывает воздействие на содержание информационной повестки дня СМИ как на ее тематическом, так и на атрибутивном уровнях.

Таким образом, содержание медийной повестки дня представляет собой результат воздействия системных механизмов, связанных с сетевым характером современного общества и особенностями политических и экономических отношений в обществе, поэтому 
различные СМИ по-разному отражают в своем новостном контенте содержание наиболее значимых для общества вопросов. Вместе с тем, цифровизация общества и появление полностью онлайн, сетевых СМИ позволяет выдвинуть предположение о том, что содержание их повестки дня может существенно отличаться от аналогичного контента традиционных СМИ, например, по причине меньшего воздействия на них со стороны различных политических акторов. По этой же причине наполнение новостного контента сетевых СМИ может быть ближе к содержанию общественной повестки дня, нежели контент традиционных СМИ. Подобные предположения выглядят вполне обоснованными, но требующими дополнительной научной верификации. Поэтому сравнительный анализ содержания информационных повесток дня разных СМИ и социальных медиа в целом является крайне актуальной задачей научного исследования. Выполнению этой задачи и посвящена данная работа.

\section{Обзор литературы}

Изучению вопросов, связанных с информационной повесткой дня в условиях современного общества, уделено немало внимания как российских, так и зарубежных ученых. Можно выделить ряд научно-исследовательских тем, активно изучаемых в данной предметной области. Одним из них является вопрос об определении понятия информационной повестки дня. По мнению М.В. Мамонова, под ней можно подразумевать «совокупность актуальных проблем и сюжетов, имеющих ряд самостоятельных характеристик» [Мамонов, 2008, с. 97]. Е.С. Дорощук рассматривает повестку дня как один из «технологических приемов повышения лояльности аудитории» [Дорощук, 2019, с. 97].

Помимо терминологических вопросов одним из важнейших аспектов изучения повестки дня является анализ ее содержательных компонентов. Как правило, в её содержании выделяют 2 уровня: тематический и атрибутивный, или «первый уровень» и «второй уровень», соответственно [Weaver, 2007, p. 142]. Выделение двух уровней содержания информационной повестки особенно целесообразно при изучении воздействия медийной и политической повесток дня на общественную. Если на «первом уровне» речь идет о том, как выражение средствами массовой информации (например, в новостных выпусках) значимости того или иного вопроса или темы влияет на значимость этого вопроса / темы в общественном сознании, то «второй уровень» подразумевает наличие определенных атрибутов в описании новостной темы, освещаемой в СМИ, которые оказывают воздействие на то, как именно аудитория будет воспринимать эту тему [Alkazemi, Wanta, 2018, p. 233].

Еще одно направление для научной рефлексии - это изучение разных типов информационных повесток дня. Традиционно выделяются 3 типа повесток дня: политическая, общественная и медийная. Как пишет А.А. Казаков, «состав и структура информационных поводов, предлагаемых прессой, зачастую могут существенно отличаться от тем, наиболее актуальных для общества и ключевых властно-политических институтов» [Казаков, 2012, с. 140]. Н.Ф. Пономарев отмечает, что «компонентами медиаповестки являются доминирующие в СМИ темы публикаций, общественной повестки - важнейшие для большинства граждан проблемы, политической повестки - первостепенные для политических акторов задачи» [Пономарев, 2010, с. 62]. На необходимость подобной классификации обращают внимание и зарубежные ученые. Р. Айсслер, А. Руссел и Б.Д. Джонс [Eissler et al., 2014] подчеркивают, что без подразделения повесток дня на общественную и политическую невозможно понять особенности воздействия медиа на процессы формирования содержания информационной повестки дня в целом.

Ряд научных работ посвящен изучению воздействия разных СМИ (как традиционных, так и современных) на формирование общественной повестки дня. М. Чонг [Chong, 2019] анализирует то, как согласуются между собой компоненты содержания повестки дня газеты The New York Times и общественной повестки дня в коммуникативном пространстве платформы поддержки микроблогов Twitter. Е. Фредерик, Л. Бурч и М. Блазцка [Frederick et al., 2015] также провели исследование данного коммуникативного простран- 
ства с целью рассмотреть особенности процесса формирования информационной повестки дня в ходе Олимпиады в Лондоне в 2012 г. Ученые выявили существенные различия между твитами, отправленными с аккаунта @London2012 (официальный канал Олимпиады в Твиттере), и твитами, содержащими хэштег \#London2012 (распространяемыми не только организаторами мероприятия, но и его зрителями).

Вообще изучение взаимного воздействия друг на друга разных повесток дня является крайне актуальным направлением научного исследования, особенно учитывая стремительную информатизацию общества и конвергентные процессы, происходящие в современных СМИ. А.В. Россошанский обращает внимание на то, что помимо формирования новостной повестки, СМИ влияют на общественное мнение, а также «программируют не только настоящее, но (в определенной степени) и будущее поведение политических акторов», что говорит о возможности сущностного воздействия медийной повестки дня на содержание политической повестки [Россошанский, 2013, с. 89]. Значимость медийной повестки и выстраиваемой ею медиарельности для общества подчеркивает и А.Г. Пастухов. Он пишет, что в условиях подмены эмпирической действительности медийной, «аудитория выстраивает свои отношения с окружающим миром, ориентируясь все чаще не на саму реальность, а на ее интерпретацию» [Пастухов, 2010, с. 178].

Одним из поднаправлений изучения информационной повестки дня является анализ используемых с ее помощью технологий. Одна из таких технологий - фрейминг. Б.Н. Шестов рассматривает фреймы «как реально существующие и активно функционирующие структурные элементы современных политикокультурных пространств, обладающие способностью мотивировать мышление и поведение субъектов политики» [Шестов, 2017, с. 361]. Д. Шойфеле и Д. Тьюксберри [Scheufele, Tewksbury, 2007] полагают, что именно изучение фрейминга позволяет получить информацию о том, как процессы описания в СМИ различных тем и их восприятие обществом влияют на формирование информационной повестки дня. Еще одна из технологий, используемая в информационной повестке дня - стигматизация, которая, как отмечают С.В. Володенков и С.Н Федорченко, «широко распространена и в современном мире политики, в условиях функционирования информационного общества и эволюции Интернета как самостоятельного онтологического пространства» [Володенков, Федорченко, 2018, с. 119].

Особой значимостью в изучении информационной повестки дня обладают методологические вопросы. В научном сообществе сложилось представление о том, что для выявления содержания медийной повестки дня целесообразно использовать в качестве прикладного метода контент-анализ [Казаков, 2011; Kligler-Vilenchiketal et al., 2014]. Общественную повестку дня, как отмечают ученые, можно определять с помощью опросов [Kligler-Vilenchik et al., 2014, p. 487], «а политическую - с помощью контент- и ивентанализа публичных выступлений, официальных заявлений и интервью представителей правящей элиты, а также событий с их участием» [Казаков, 2011, с. 72].

Данная работа нацелена на изучение соотношения содержания повесток дня СМИ и социальных медиа. Причём в ней рассматриваются повестки дня разных СМИ, как традиционных, так и «новых» (подробнее об отличиях различных типов СМИ см., например, [Балуев, 2013]).

\section{Объекты и методы}

В качестве одного из основных прикладных методов в исследовании используется качественно-количественный тип контент-анализа. Он является релевантным научным инструментом для рассмотрения новостных заголовков традиционных СМИ, сетевых интернет-изданий, информационных агентств и наиболее популярных тем обсуждений в социальных медиа. В соответствии с целями нашего исследования контент-анализ проводится на основании данных одного из традиционных СМИ - телевизионного канала НТВ ${ }^{1}$,

${ }^{1}$ Официальный сайт телеканала HTB. URL: https://www.ntv.ru (дата обращения: 29.01.2020) 
интернет-издания Lenta. Ru ${ }^{1}$, информационного агентства России TACC ${ }^{2}$ и социальных медиа (изучались наиболее популярные темы, рейтинг которых составлен новостным агрегатором MediaMetrics ${ }^{3}$ ). В качестве единицы контент-анализа в работе выступает тема (в работе изучается именно тематический уровень повестки дня), а единица счета - новостные заголовки.

Мониторинг новостных заголовков осуществлялся с 13 по 29 января 2020 г., начиная с 21:00 (по нашему мнению, к указанному времени дневная информационная повестка в целом уже сформирована). Продолжительность выбранного временного промежутка для проведения контент-анализа новостных лент позволяет сделать релевантные выводы относительно проблематики текущего исследования. В ходе проведения анализа рассматривались 10 последних (по времени опубликования к моменту проведения наблюдения) заголовков новостей, т.е. рассматривались только те новостные заголовки, которые представлены на официальных сайтах указанных СМИ как основные и последние (свежие) по времени их публикации в момент осуществления наблюдения.

В ходе контент-анализа ежедневно заполнялась таблица. Каждый день в эту таблицу вносились по десять новостных заголовков каждого из указанных СМИ и социальных медиа, которые в дальнейшем подвергались сравнительному анализу. На основании ещё одного метода - сравнительного анализа - выявлялось, сколько тем (из 10 возможных) совпадают у разных СМИ (в том числе - между собой) и социальных медиа. На основании этого сравнения высчитывался коэффициент сопряженности информационной повестки дня по следующей формуле: соотношение общего (за 17 дней наблюдений) количества совпадающих тем к потенциально возможному количеству совпадающих тем (оно равнялось 170, так как наблюдение проводилось в течение 17 дней, а максимально возможное число совпадений за один день наблюдения - 10). Таким образом, с помощью коэффициента сопряженности можно установить, содержание повесток дня каких СМИ ближе остальных содержанию повестки дня социальных медиа, а также повестки дня каких СМИ наиболее близки между собой.

Значения коэффициента сопряженности могут располагаться в диапазоне от 0 до 1, где 0 означает отсутствие совпадений в содержании разных повесток дня, а 1 - это максимально возможное число совпадений тем, составляющих изучаемые повестки дня. Чем выше коэффициент сопряженности информационной повестки дня между разными СМИ, тем больше совпадений содержат эти повестки, тем ближе их содержание друг другу. Чем выше коэффициент сопряженности повесток дня СМИ и социальных медиа, тем больше и точнее перечень главных новостных заголовков соответствует значительной части общественного мнения.

Помимо сравнения значений обозначенного коэффициента сопряженности по конкретным новостным заголовкам разных СМИ и социальных медиа, дополнительно проведен сравнительный анализ наиболее популярных обобщенных тем, которым посвящены анализируемые новостные заголовки. Сравнение наиболее популярных новостных рубрик позволит также сделать выводы о соответствии повесток дня СМИ и социальных медиа на содержательном уровне.

\section{Результаты}

Мониторинг новостных заголовков проводился в течение 17 дней, по результатам которого были проанализированы 680 заголовков с интернет-страниц официальных сайтов HTB, Lenta.Ru, TACC и социальных медиа. Ежедневные списки с новостными заго-

${ }^{1}$ Официальный сайт Lenta.Ru. URL: https://lenta.ru (дата обращения: 29.01.2020)

${ }^{2}$ Официальный сайт информационного агентства России TACC. URL: https://tass.ru (дата обращения: 29.01.2020)

${ }^{3}$ Официальный сайт MediaMetrics. UR1: https://mediametrics.ru/rating/ru/online.html (дата обращения: 29.01.2020) 
ловками, представленными в СМИ, сравнивались между собой, а также со списками наиболее читаемых тем в социальных медиа. По итогам этих сравнений выявлена общая доля совпадений информационных повесток изучаемых СМИ и социальных медиа, так называемый коэффициент сопряженности. Числовые значения коэффициента сопряженности информационных повесток дня между разными СМИ и социальными медиа представлены в табл. 1.

Таблица 1

Table 1

Значения коэффициента сопряженности информационных повесток дня Conjugation coefficient indicators of agenda

\begin{tabular}{|l|c|c|c|c|}
\hline $\begin{array}{c}\text { Название субъекта } \\
\text { информационной } \\
\text { повестки дня }\end{array}$ & HTB & Lenta.Ru & ТАCC & $\begin{array}{c}\text { МеdiaМеtrics } \\
\text { (социальные } \\
\text { медиа) }\end{array}$ \\
\hline HTB & - & 0,15 & 0,19 & 0,06 \\
\hline Lenta.Ru & 0,15 & - & 0,16 & 0,06 \\
\hline TACC & 0,19 & 0,16 & - & 0,06 \\
\hline $\begin{array}{l}\text { МediaМetrics } \\
\text { социальные медиа) }\end{array}$ & 0,06 & 0,06 & 0,06 & - \\
\hline
\end{tabular}

Наивысшее (относительное) значение коэффициента сопряженности наблюдается между информационными повестками дня ТАСС и НТВ $(0,19)$, меньшее значение этого коэффициента - у информационных повесток дня ТАСС и Lenta.ru $(0,16)$, а также - НТВ и Lenta.ru $(0,15)$. Коэффициент сопряженности между информационными повестками дня всех СМИ, рассмотренных в данной работе и повесткой дня социальных медиа одинаков и составляет 0,06. Интерпретация полученных значений коэффициента сопряженности информационных повесток дня будет произведена в следующей части работы.

Дополнительно отметим динамику изменений коэффициента сопряженности всех медийных повесток и общественной повестки дня в течение всего периода проведения мониторинга. Результаты представлены на рис. 1.

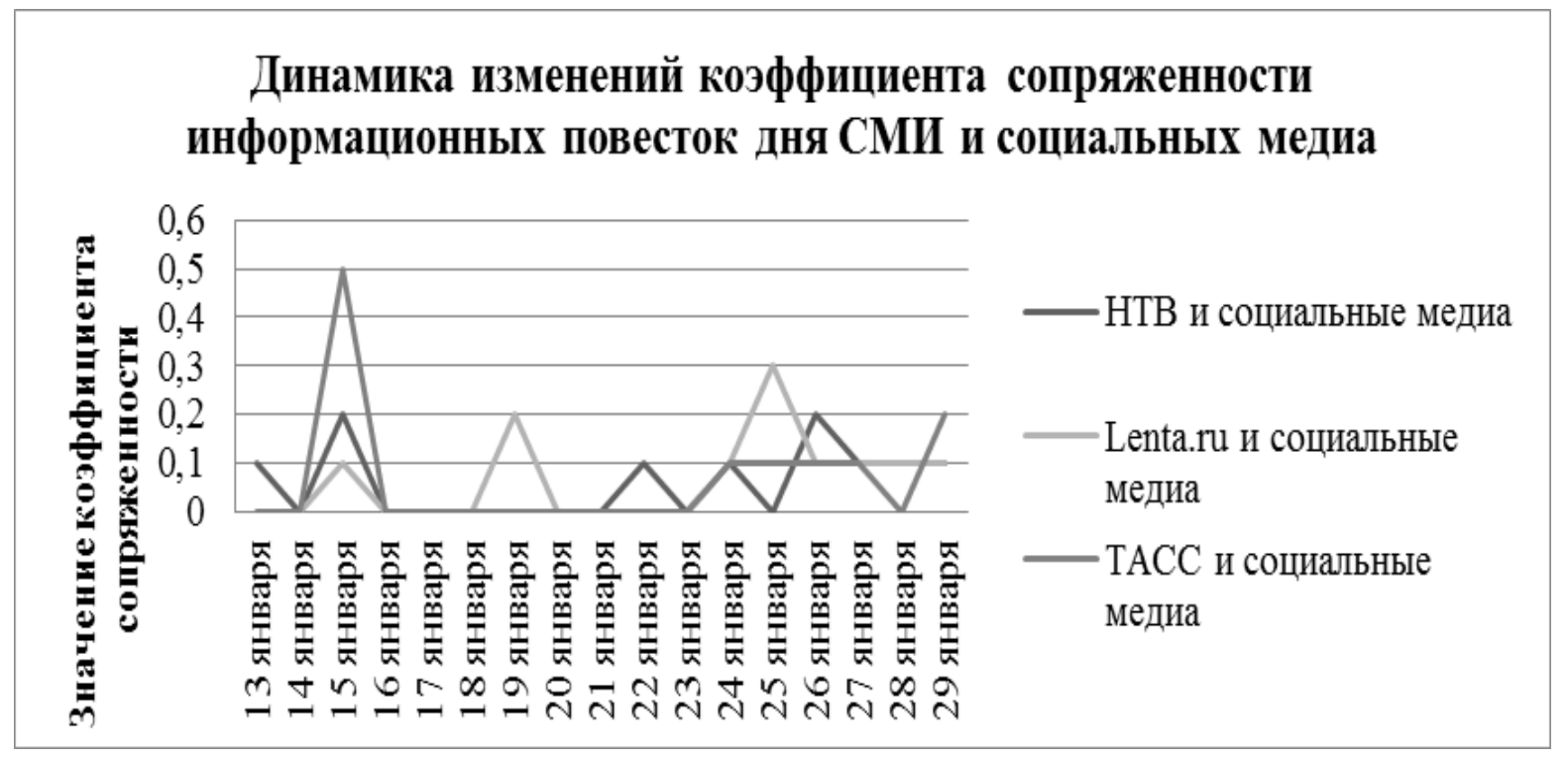

Рис. 1. Динамика изменений коэффициента сопряженности информационных повесток дня СМИ и социальных медиа по дням

Fig. 1. The dynamics of changes in the coefficient of conjugation of media and social media agendas by days 
Согласно данным диаграммы, наименьший размах вариации значений коэффициента сопряженности наблюдается между информационными повестками дня НТВ и социальных медиа, а наивысший - у ТАСС и социальных медиа. Наивысшее промежуточное значение коэффициент сопряженности принимает 15 января в соотношении информационных повесток дня социальных медиа и ТАСС. Вместе с тем с 16 по 23 января включительно в содержании повесток дня ТАСС и социальных медиа вообще не было никаких совпадений, что является наиболее продолжительным показателем среди всех остальных. Наиболее продолжительный период наблюдения, когда у одной из повесток дня того или иного СМИ была хотя бы одна совпадающая с повесткой дня социальных медиа общая тема - это период с 24 по 29 января включительно, когда наблюдались совпадения в содержании информационных повесток дня Lenta.ru и социальных медиа.

Помимо измерения и сравнения количественных показателей коэффициента сопряженности информационных повесток дня, важным инструментом для заявленного в работе сравнительного анализа является изучение наиболее популярных в СМИ и социальных медиа обобщенных тем. Поэтому в ходе мониторинга выявлялись не только совпадающие и близкие новостные заголовки, но и фиксировалась их обобщенная тематика. Выделен ряд рубрик, некоторые из которых требуют дополнительного уточнения. Например, в рубрику «Внутренняя политика» были отнесены сообщения по тематике внутренней политики России, в рубрику «Внешняя политика» - новостные заголовки по теме внешней политики России. Рубрику «Мировая политика и международные процессы» составили новостные сообщения, посвященные отношениям зарубежных государств между собой, а также их внутриполитическим событиям и процессам. Результаты обобщеннотематического распределения новостных заголовков изучаемых СМИ и социальных медиа представлены в табл. 2.

Таблица 2 Table 2

Обобщенно-тематическое распределение новостных заголовков Generalized thematic distribution of news headlines

\begin{tabular}{|l|c|c|c|c|}
\hline \multicolumn{1}{|c|}{ Тема } & ТАСС & $\begin{array}{c}\text { Телеканал } \\
\text { НТВ }\end{array}$ & Lenta.Ru & $\begin{array}{c}\text { Социальные медиа } \\
\text { (по данным } \\
\text { MediaMetrics) }\end{array}$ \\
\hline $\begin{array}{l}\text { Мировая политика } \\
\text { и международные процессы }\end{array}$ & 46 & 21 & 15 & 1 \\
\hline Внешняя политика & 22 & 9 & 13 & 2 \\
\hline Происшествие & 24 & 37 & 10 & 77 \\
\hline Внутренняя политика & 21 & 25 & 17 & 28 \\
\hline Социальная сфера & 20 & 30 & 26 & 1 \\
\hline Спорт & 12 & 9 & 14 & 7 \\
\hline Экономика & 10 & 4 & 14 & 9 \\
\hline $\begin{array}{l}\text { Культура, музыка, искусство, } \\
\text { кино }\end{array}$ & 3 & 20 & 14 & 2 \\
\hline История & 9 & 11 & 10 & 3 \\
\hline Наука и технологии & 3 & 1 & 7 & 1 \\
\hline $\begin{array}{l}\text { Вопросы безопасности } \\
\text { и обороны }\end{array}$ & 1 & 1 & 1 & 2 \\
\hline СМИ & 1 & 3 & 1 & 0 \\
\hline Погода & 0 & 9 & 0 & 0 \\
\hline Официальные праздники & 0 & 1 & & 24 \\
\hline
\end{tabular}


По результатам данного распределения, наиболее обсуждаемыми в социальных медиа новостными заголовками оказались сообщения, посвященные различным происшествиям, на втором месте (с существенным отставанием) - сообщения, посвященные внутренней политике России, на третьем - новостные заголовки, связанные с социальной сферой.

В сетевом интернет-издании именно тематика, связанная с социальной сферой, стала наиболее популярной в новостных сообщениях (хотя без существенного отрыва от остальных тем, как в случае с общественной повесткой дня), на втором месте по частоте встречаемости находятся новостные заголовки по теме внутренней политики России, а на третьем - по тематике политических процессов и отношений между иностранными государствами, а также их внутриполитических событий.

В информационной повестке дня агентства ТАСС чаще всего (причем с ощутимым перевесом над остальными темами) встречались новостные заголовки по теме «Мировая политика и международные процессы», заметно реже новостные сообщения посвящались теме происшествий. На третьем месте по популярности - тема внешней политики России (заметим, популярность внутриполитической и социальной тематик уступают ей совсем незначительно).

Для информационной повестки дня телевизионного канала характерно преобладание новостных заголовков, посвященных теме происшествий, а также тематикам, связанным с социальной сферой и внутренней политикой. Обращает на себя внимание последовательное распределение внимания к новостным сообщениям по основным темам, т.е. отсутствие существенных разрывов в частоте упоминаемости между соседними тематиками (повторимся, это касается основных тем).

\section{Обсуждение}

Результаты проведенного анализа позволяют сделать ряд выводов. Во-первых, обращают на себя внимание невысокие показатели коэффициента сопряженности информационной повестки дня изучаемых в работе СМИ. Причем все показатели данного коэффициента медийных повесток дня примерно схожи и варьрируются в числовом диапазоне от 0,15 до 0,19. Объяснением подобной ситуации может быть то, что, как уже отмечалось, содержание медийной повестки дня представляет собой результат воздействия системных механизмов, связанных как с особенностями цифровизации современного общества, так и с характером политических и экономических отношений. Конкретные содержательные элементы и их взаимосвязи на тематическом (изучаемом в данной работе) и атрибутивном уровнях медийной повестки дня зависят от действий не только медийных акторов (самих СМИ), но и политических субъектов и общества в целом. Степень и характер воздействия на формирование повестки дня определяют то, какие новостные события, происходящие внутри государства и за его пределами в тот или иной период времени, оказываются представленными в структуре повестки дня, а какие - нет, а также влияют на то, как именно они представлены. Поэтому в условиях одного событийного ряда разными современными СМИ отбираются те или иные темы и конкретные фреймы для их представления. Причем в условиях высокой степени информатизации общества контент отбирается из большого массива данных. Вероятнее всего, этим и объясняется невысокая степень совпадения информационных повесток дня изучаемых в работе СМИ.

Подобный результат подтверждает идею о том, что в современном информационном обществе публичное пространство разделено на несколько коммуникативных полей с преобладающими в них (подчас существенно отличными друг от друга) нарративами. Различные по своему содержанию информационные повестки дня разных СМИ являются, своего рода, символами существования подобных коммуникативных полей. Для детального изучения преобладающих в них нарративов особенно полезным является анализ содер- 
жания атрибутивного уровня информационной повестки дня (в нашей работе рассматривается тематический уровень).

Во-вторых, совсем не высокий показатель коэффициента сопряженности $(0,06)$ наблюдается между информационными повестками дня всех рассмотренных СМИ, с одной стороны, и социальных медиа - с другой. Причем, во всех трех случаях этот показатель одинаков. Этот результат актуализирует сразу несколько аспектов. Первый аспект заключается в том, насколько точно современные СМИ отражают общественное мнение. Чем выше показатель коэффициента сопряженности информационных повесток дня СМИ, с одной стороны, и социальных медиа - с другой, тем точнее СМИ отражают значительную часть общественных настроений. Результаты данного исследования демонстрируют, что степень отражения общественного мнения в СМИ незначительна. Однако, повторимся, что содержание медийной повестки дня определяется не только общественными действиями и настроениями, но и активностью политических субъектов, а также самих СМИ. Это, в какой-то степени, объясняет полученные результаты. Здесь же необходимо отметить и один методический аспект, который отчасти оказал воздействие на результаты проведенного контент-анализа. Он заключается в том, что нередко в социальных медиа среди десяти наиболее читаемых новостей находятся несколько сообщений примерно по одной и той же теме, но при подсчете эти сообщения все же использовались как разные темы, так как в них актуализировались разные (существенные) аспекты, способные изменить саму новостную основу этого сообщения. В этом случае засчитывать несколько сообщений по примерно близкой теме в качестве одной единицы анализа, на наш взгляд, противоречит требованию проведения исследования именно наиболее актуальных новостных сообщений, вызвавших оживленную дискуссию в обществе.

Второй аспект связан с тем, что вне зависимости от типа СМИ (традиционное или современное, сетевое) значение показателя коэффициента сопряженности их информационных повесток дня и повестки дня социальных медиа одинаково. Впрочем, в работе рассматривались новостные данные только нескольких СМИ, что существенно сужает возможности экстраполяции полученных результатов и является одним из ограничений данного исследования. Однако в контексте изучения взаимодействия общества и СМИ данный аспект крайне примечателен, например, в плане изучения содержания повесток дня сетевых интернет-изданий и социальных медиа.

В-третьих, отдельно отметим динамику изменений числа совпадений в информационных повестках дня социальных медиа и СМИ в течение изучаемого периода времени. Обращает на себя внимание, что наиболее продолжительный период, когда между двумя повестками дня были какие-либо тематические совпадения, наблюдался между повесткой дня социальных медиа и сетевого интернет-издания. Это подтверждает тезис о том, что сетевые издания точнее отражают общественное мнение. Вместе с тем, максимальное число совпадений в содержании повесток дня СМИ и социальных медиа случилось 15 января, когда между повестками дня ТАСС и социальных медиа насчитывалось 5 тематических совпадений. При этом, отметим, что именно между повестками дня ТАСС и социальных медиа наблюдалось отсутствие пересечений на протяжении 8 дней мониторинга новостных заголовков.

В-четвёртых, сравнительный анализ тематического распределения новостных заголовков продемонстрировал наибольшее совпадение между содержанием новостной повестки дня телевизионного канала и повесткой дня социальных медиа: в обоих случаях, чаще остальных, встречаются новостные заголовки, посвященные различным происшествиям (хотя в повестке дня социальных медиа это проявляется ощутимо заметнее); второе и третье места по частоте встречаемости занимают темы, связанные с социальной сферой и внутренней политикой (хотя порядок их расположения в указанных повестках дня - разный). 
Говоря о тематических пересечениях повесток дня СМИ между собой, отмечаем, что применительно к перечню основных (представленных чаще остальных) тем наиболее соответствует друг другу содержание повесток дня телевизионного канала и сетевого интернет-издания. Если сравнивать по три наиболее часто встречаемых темы новостных заголовков в повестке дня телеканала, интернет-издания и ТАСС, то именно между первыми двумя СМИ присутствует наиболее точное пересечение. Тематически их объединяют новостные заголовки, посвященные областям социальной сферы и вопросам внутренней политики России.

Таким образом, сравнительный анализ коэффициентов сопряженности и тематического распределения содержания информационных повесток дня является валидным инструментом для измерения повесток дня социальных медиа и СМИ. Применение данного научноисследовательского инструментария позволяет сформулировать выводы о том, насколько (как в статистическом, так и в содержательном смыслах) пересекается между собой содержание повесток дня разных СМИ (в том числе - между собой) и социальных медиа.

\section{Выводы}

Результаты исследования согласуются с существующим тезисом о дифференциации современного публичного пространства. Складывающиеся в нем коммуникативные (и содержательно-смысловые) поля характеризуются подчас отличными друг от друга нарративами, а несхожесть медийных повесток дня в этом отношении выступает неким символом подобных различий. Показатели коэффициента сопряженности между информационными повестками дня СМИ и социальных медиа, установленные по ходу проведения контент- и сравнительного анализа, выдвигают на передний план вопрос об особенностях процесса установления медийной повестки дня и участия в нем различных политических и общественных акторов. Вместе с тем, выполненное исследование позволяет выделить те общие тематические направления, которые объединяют информационные повестки дня социальных медиа и СМИ (это, в первую очередь, темы, посвященные происшествиям, вопросам социальной сферы и внутренней политике России), а также повестки дня разных СМИ между собой (это, прежде всего, темы, посвященные социальной сфере и вопросам внутренней политики России).

Впрочем, в проведенном исследовании есть и ряд ограничений: в работе анализируются информационные повестки дня только трех СМИ (возможно, для более глобальных выводов необходим больший масштаб исследования). Кроме того, мониторинг новостных заголовков осуществлялся один раз в день (в определенный момент времени). Расширение темпоральных рамок ежедневного мониторинга может оказать существенное влияние на результаты исследования.

\section{Список литературы}

1. Балуев Д.Г. 2013. Политическая роль социальных медиа как поле научного исследования. Образовательные технологии и общество, 16 (2): 604-616.

2. Володенков С.В., Федорченко С.Н. 2018. Цифровые стигматы как инструмент манипуляции массовым сознанием в условиях современного государства и общества. Социологические исследования, 11: 117-123. DOI: 10.31857/S013216250002791-3

3. Дорощук Е.С. 2019. Повестка дня как фактор формирования лояльности аудитории регионального телеканала: коммуникационный аспект. В кн. Медиа в современном мире. 58-е Петербургские чтения. Коммуникации в медиаиндустрии: акторы, технологии, тренды. Сборник материалов круглого стола Междунарадного научного форума, г. Санкт-Петербург, 18-19 апреля 2019 года. В 2-х т. Т. 1. Под ред. В.В. Васильевой. СПб., СПбГУ: 96-98.

4. Казаков А.А. 2011. Взаимодействие информационной и политической «повесток дня»: к постановке проблемы. Известия Саратовского университета. Новая серия. Серия: Социология. Политология, 11(3): 70-73. 
5. Казаков А.А. 2012. Теоретико-методологический потенциал категории «медийная повестка дня»: возможности и ограничения. Вестник Волгоградского государственного университета. Серия 4: История. Регионоведение. Международные отношения, 1 (21): 138-143.

6. Мамонов М.В. 2008. Роль политических субъектов в формировании приоритетов межличностной «повестки дня» россиян. Политическая экспертиза: ПОЛИТЭКС, 4 (3): 97-105.

7. Пастухов А.Г. 2010. Agenda setting, или установление повестки дня в медиатексте. В кн. Медиатекст: стратегии - функции - стиль. Под ред. Т.В. Чернышовой. Орёл, ООО «Горизонт»: $171-185$.

8. Пономарев Н.Ф. 2010. Фрейминг медиаповестки дня и типология медиафреймов. Вестник Пермского университета. Российская и зарубежная филология, 3 (9): 62-69.

9. Россошанский А.В. 2013. «Новостные ценности» российских СМИ. Известия Саратовского университета. Новая серия. Серия: Социология. Политология, 13 (4): 89-92.

10. Шестов Б.Н. 2017. Медийные технологии влияния на политическую культуру. Известия Саратовского университета. Новая серия. Серия: Социология. Политология, 17 (3): 358-364.

11. Alkazemi M.F., Wanta W. 2018. The Effect of Oil Prices on the Media Agenda: A Model of Agenda Building. Newspaper Research Journal, $39(2)$ : 232-244. DOI: https://doi.org /10.1177/0739532918775655.

12. Chong M. 2019. Connective Power of the Twitter Networks: Discovering the Reverse Agenda-Setting Effects of Hashtag Activism Through Topic Modeling. The 82nd Annual Meeting of the Association for Information Science \& Technology. Melbourne, Australia. 19-23 October 2019, 56 (1): 629-630. DOI: 10.1002/pra2.113.

13. Eissler R., Russel A., Jones B.D. 2015. New Avenues for the Study of Agenda Setting. The Policy Studies Journal, 42 (S1): 71-86.

14. Frederick E.L., Burch L.M., Blaszka M. 2015. A shift in set: Examining the Presence of Agenda Setting on Twitter During the 2012 London Olympics. Communication \& Sport, 3(3): 312-333. DOI: $10.1177 / 2167479513508393$.

15. Kligler-Vilenchik N., Tsfati Ya., Meyers O. 2014. Setting the Collective Memory Agenda: Examining Mainstream Media Influence on Individuals' Perceptions of the Past. Memory Studies, 7(4): 484-499. DOI: $10.1177 / 1750698014523443$.

16. Scheufele D.A., Tewksbury D. 2007. Framing, agenda setting, and priming: The evolution of three media effects models. Journal of Communication, 57 (1): 9-20. DOI: http://dx.doi.org/10.1111/j.0021-9916.2007. 00326.x.

17. Weaver D.H. 2007. Thoughts on Agenda Setting, Framing, and Priming. Journal of Communication, 57 (1): 142-147. DOI: https://www.researchgate.net/deref/http\%3A\%2F\%2Fdx.doi.org \%2F10.1111\%2Fj.1460-2466.2006.00333.x.

\section{References}

1. Baluev D.G. 2013. Politicheskaya rol' sotsial'nykh media kak pole nauchnogo issledovaniya [The Political Role of Social Media as a Field of Research]. Educational Technology \& Society, 16 (2): 604-616.

2. Volodenkov S.V., Fedorchenko S.N. 2018. Tsifrovye stigmaty kak instrument manipulyatsii massovym soznaniem v usloviyakh sovremennogo gosudarstva i obshchestva [Digital stigmata as a tool for manipulating mass consciousness in a modern state and society]. Sociological Studies, 11: 117-123. DOI: $10.31857 / \mathrm{S} 013216250002791-3$

3. Doroshchuk E.S. 2019. Povestka dnya kak faktor formirovaniya loyal'nosti auditorii regional'nogo telekanala: kommunikatsionnyy aspekt [Agenda as a Factor in Forming Audience Loyalty of a Regional TV Channel: Communication Aspect]. In: Media v sovremennom mire. 58-e Peterburgskie chteniya [Media in the modern world. 58th Petersburg Readings]. Kommunikatsii v mediaindustrii: aktory, tekhnologii, trendy [Communication in the media industry: actors, technologies, trends]. Collection of materials of the round table of the international Scientific forum, St. Petersburg, April 1819, 2019. In 2 vols. Vol. 1. Under the editorship of V. V. Vasilyeva. SPb., Publ. SPbGU: 96-98.

4. Kazakov A.A. 2011. Vzaimodeystvie informatsionnoy i politicheskoy «povestok dnya»: k postanovke problemy [Interaction of information and political "agendas": to the problem statement]. Izvestiya of Saratov University. New Series. Series: Sociology. Politology, 11(3): 70-73. 
5. Kazakov A.A. 2012. Teoretiko-metodologicheskiy potentsial kategorii «mediynaya povestka dnya»: vozmozhnosti i ogranicheniya [Theoretical and methodological potential of the "media agenda" category: opportunities and limitations]. Vestnik Volgogradskogo gosudarstvennogo universiteta. Ser. 4: Istoriya. Regionovedenie. Mezhdunarodnye otnosheniya, 1 (21): 138-143.

6. Mamonov M.V. 2008. Rol' politicheskikh sub"ektov $\mathrm{v}$ formirovanii prioritetov mezhlichnostnoy «povestki dnya» rossiyan [The role of political actors in the formation of the priorities of the interpersonal "agenda" of Russians]. Political expertise: POLITEX, 3: 97-105.

7. Pastukhov A.G. 2010. Agenda setting, ili ustanovlenie povestki dnya v mediatekste [Agenda setting, or setting the agenda in media text]. In: Mediatekst: strategii - funktsii - stil'. Ed. T.V. Chernyshova. Orel, Publ. Gorizont: 171-185.

8. Ponomarev N.F. 2010. Freyming mediapovestki dnya i tipologiya mediafreymov [Framing the media agenda and typology of media frames]. Perm University Herald. Russian and Foreign Philology, 3 (9): $62-69$.

9. Rossoshanskiy A.V. 2013. "Novostnye tsennosti" rossiyskikh SMI ["News values" of the Russian media]. Izvestiya of Saratov University. New Series. Series: Sociology. Politology, 13 (4): 89-92.

10.Shestov B.N. 2017. Mediynye tekhnologii vliyaniya na politicheskuyu kul'turu [Media technologies to influence political culture]. Izvestiya of Saratov University. New Series. Series: Sociology. Politology, 17 (3): 358-364.

11.Alkazemi M.F., Wanta W. 2018. The Effect of Oil Prices on the Media Agenda: A Model of Agenda Building. Newspaper Research Journal, 39 (2): 232-244. DOI: https://doi.org /10.1177/0739532918775655.

12.Chong M. 2019. Connective Power of the Twitter Networks: Discovering the Reverse Agenda-Setting Effects of Hashtag Activism Through Topic Modeling. The 82nd Annual Meeting of the Association for Information Science \& Technology. Melbourne, Australia. 19-23 October 2019, 56 (1): 629-630. DOI: 10.1002/pra2.113

13.Eissler R., Russel A., Jones B.D. 2015. New Avenues for the Study of Agenda Setting. The Policy Studies Journal, 42 (S1): 71-86.

14.Frederick E.L., Burch L.M., Blaszka M. 2015. A shift in set: Examining the presence of agenda setting on Twitter during the 2012 London Olympics. Communication \& Sport, 3(3): 312-333. DOI: $10.1177 / 2167479513508393$.

15.Kligler-Vilenchik N., Tsfati Ya., Meyers O. 2014. Setting the collective memory agenda: Examining mainstream media influence on individuals' perceptions of the past. Memory Studies, 7(4): 484-499. DOI: $10.1177 / 1750698014523443$.

16.Scheufele D.A., Tewksbury D. 2007. Framing, agenda setting, and priming: The evolution of three media effects models. Journal of Communication, 57 (1): 9-20. DOI: http://dx.doi.org/10.1111/j.0021-9916.2007. 00326.x.

17.Weaver D.H. 2007. Thoughts on Agenda Setting, Framing, and Priming. Journal of Communication, 57 (1): 142-147. DOI: https://www.researchgate.net/deref/http\%3A\%2F \%2Fdx.doi.org\%2F10.1111\%2Fj.1460-2466.2006.00333.x.

\section{ИНФОРМАЦИЯ ОБ АВТОРЕ}

Каминченко Дмитрий Игоревич, кандидат политических наук, старший преподаватель кафедры прикладного политического анализа и моделирования национального исследовательского Нижегородского государственного университета им. Н.И. Лобачевского, г. Нижний Новгород, Россия.

\section{INFORMATION ABOUT THE AUTHOR}

Dmitry I. Kaminchenko, Candidate of Pedagogical Sciences, Senior Lecturer, Department of Applied Analysis and Modeling, National Research Nizhny Novgorod State University named after N.I. Lobachevsky, Nizhny Novgorod, Russia. 